\title{
Usability of a new disposable autoinjector platform device: results of a formative study conducted with a broad user population
}

This article was published in the following Dove Press journal:

Medical Devices: Evidence and Research

3 June 2015

Number of times this article has been viewed

\author{
Jakob Lange' \\ Philipp Richard' \\ Nick Bradley ${ }^{2}$ \\ 'Ypsomed AG, Burgdorf, Switzerland; \\ ${ }^{2}$ BERGO UK, Bearsden, Glasgow, UK
}

\begin{abstract}
This article presents a late-stage formative usability study of an autoinjector platform device. Such devices are used for the subcutaneous delivery of biopharmaceuticals, primarily for self-administration by the patient. Previous usability work on autoinjectors reported in the literature has been specific to single indications. This study was instead conducted with a broad user population, defined to represent user characteristics across a range of indications. The goals of the study were to evaluate whether users could use the devices safely and effectively, and could understand the instructions for use (IFU) as well as the accompanying training. Further objectives were to capture any usability issues and to obtain participants' subjective ratings on the IFU and training as well as the confidence and comfort in using the device. A total of 43 participants in 5 groups received training and performed simulated injections either into an injection pad or a mannequin. All participants were able to successfully use the device. The device was well appreciated by all users, with a reported degree of confidence in using the device of $98 \%$, of user comfort of $93 \%$, and of comprehensibility of IFU and training of $98 \%$. These values are higher than other comparable results reported in the literature. The presence of both audible and visible feedback during injection was seen to be a significant factor contributing to injection success. The observation that the device can be safely and efficiently used by all tested user groups provides confidence that the device and IFU in their current form will pass future summative testing in specific applications.
\end{abstract}

Keywords: human factors engineering, autoinjector, handling study, use error, instructions for use, YpsoMate ${ }^{\mathrm{TM}}$

\section{Introduction}

Autoinjectors provide a convenient alternative to manual syringe injections for the subcutaneous administration of drugs across a range of indications. ${ }^{1,2}$ Such devices, allowing the patient to self-inject, have been in use for more than a decade and have been shown to increase patient adherence and compliance during treatment of autoimmune inflammatory diseases such as rheumatoid arthritis and multiple sclerosis. ${ }^{3-10}$ There are currently a number of different autoinjectors with different operating principles and varying degrees of automation available to patients. ${ }^{1,11}$ Recently, there has been a trend to move from more complex, fully automated button-activated technologies to simpler push-on-skin activated devices which offer the same level of user comfort with fewer user steps and simpler device design. ${ }^{11}$

The application of knowledge of human capabilities and limitations to the design of artifacts, also known as usability or human factors, forms a central part in the development of safe and reliable medical devices such as autoinjectors. The documented
Correspondence: Jakob Lange Ypsomed AG, Brunnmattstrasse 6, $\mathrm{CH}-340$ I Burgdorf, Switzerland Tel +4I 344243187

Fax +4I 344243 I5I

Email jakob.lange@ypsomed.com 
application of usability methods, including usability testing, throughout the design cycle is also required by regulatory authorities. ${ }^{12-14}$ Usability testing during development is usually divided into three parts. First, during early development, early-stage formative studies are conducted with the aim of providing user feedback to iteratively refine the device design and instructions for use (IFU). Later, toward the end of development, late-stage formative tests are performed to confirm that the device is suitable for its intended use and likely to pass the usability part of design validation. Finally, summative testing, also known as usability validation, is carried out to provide objective evidence that the intended use has been met and that the device can be reliably and safely used by the intended user population. ${ }^{15}$

Current guidance on the application of usability methods to medical device development is focused on single indications and provides no recommendations on dealing with device platforms intended to be used across multiple indications. ${ }^{12-15}$ One possibility to deal with this gap has been developed by the authors and applied to a pen injector device in a previous study. ${ }^{16}$ The approach consists of performing testing in two stages, first, subjecting the platform device to formative testing with a broad user population recruited to reflect general user characteristics rather than those for a specific indication. The second stage comprises customizing the device for a given application and conducting further formative testing followed by usability validation with the corresponding specific user population.

All of the usability work on autoinjectors reported in the literature has been specific to a single indication, and most of it has been in the form of clinical studies assessing patient compliance and ease of use of a single device, comparing different devices against each other or a device against a syringe. ${ }^{3-10}$ Some formative handling studies, analyzing user behavior with the aim of identifying potential user errors and providing design input, have been reported. ${ }^{17-20}$ Some of these studies contain elements of design validation although they, with the possible exception of the validation of a specific sharps injury prevention feature, do not report full formal summative study results. ${ }^{18,20}$

This article presents a late-stage formative study of a platform autoinjector with a user population defined to represent user properties across a broad range of indications. Specifically, the study was designed and carried out with the aim of understanding whether the platform device, its IFU, and the accompanying user training are suitable for users in all targeted applications and whether the autoinjector would be likely to pass future summative testing in specific indications.

\section{Materials and methods Objectives}

In this late-stage formative study, the primary objective was to evaluate whether a broad user population can use the YpsoMate ${ }^{\mathrm{TM}}$ (Ypsomed AG, Burgdorf, Switzerland) platform prototype devices safely and effectively and can understand the IFU and the accompanying training. Further objectives were to capture any usability issues that may affect user performance and satisfaction and to obtain participants' subjective ratings on the helpfulness of the IFU and training as well as the confidence and hand comfort in using the device.

\section{Study device}

The YpsoMate ${ }^{\mathrm{TM}}$ (Ypsomed AG) is a single-dose, singleuse, two-step autoinjector intended for the subcutaneous self-injection of drugs in the context of various treatments requiring relatively infrequent (weekly, biweekly, or monthly) injections of a single-fixed dose. ${ }^{21}$ The device contains a $1 \mathrm{~mL}$ long prefilled syringe and features automated delivery of the drug to the subcutaneous tissue once triggered by pushing the device on skin. The device is presented in Figure 1. The tasks performed by the user to perform an injection are shown in Figure 2 and chiefly involve the actions of removing a protective cap, placing the device onto the skin, pushing down to start the injection, interpreting an "end" click, holding down for another 5 seconds, and then disposing of the device.

\section{Participants and groups}

The YpsoMate ${ }^{\mathrm{TM}}$ (Ypsomed AG) has been developed as a platform device, implying that it will be used for a number of different therapies. Therefore, no specific user population has been defined for the development of the platform. Rather, a broader view of device use was taken, focusing on

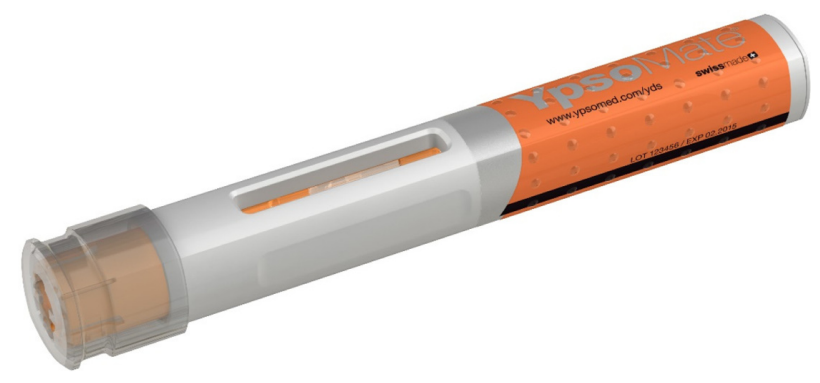

Figure I The YpsoMate ${ }^{\mathrm{TM}}$ disposable autoinjector used in the study. 


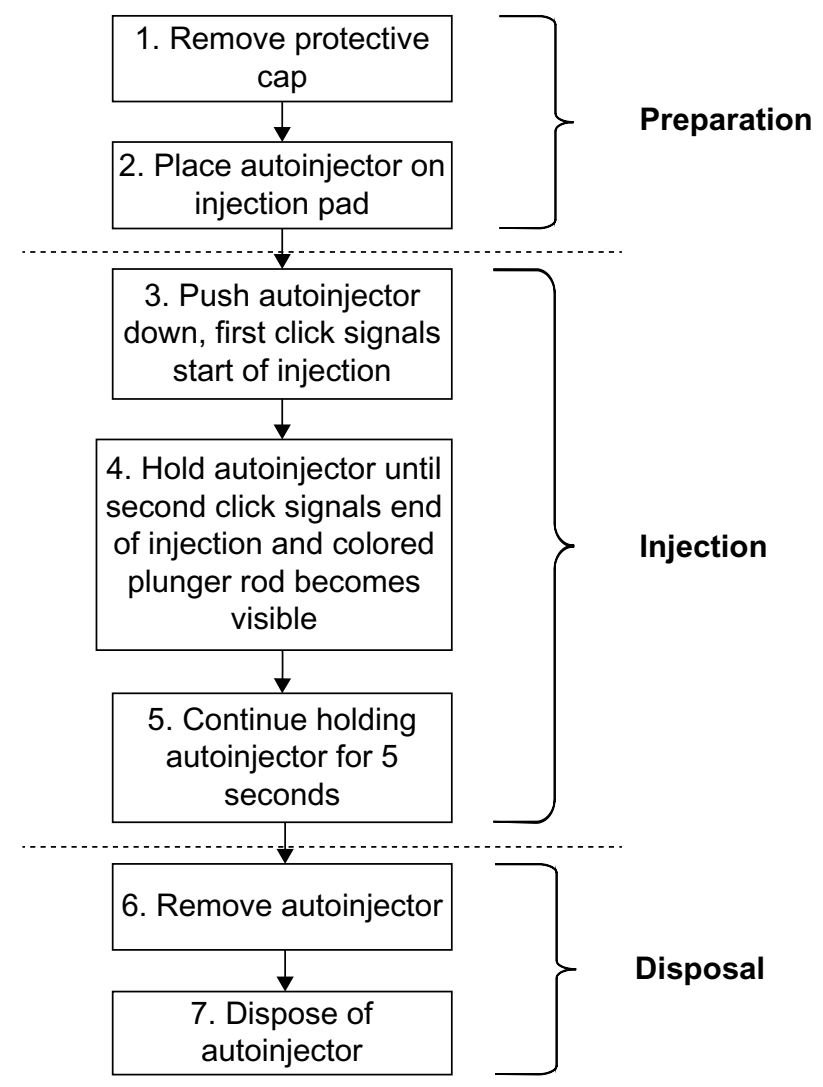

Figure 2 Tasks performed by the user during an injection.

impairments rather than illnesses. The device may be used by patients to inject a drug into themselves or may be used by another person, typically a health care professional (HCP) or a caregiver (CG), to inject drug into a patient who is unable to perform this task themselves.

Against this background, different user groups were defined, with the aim of selecting relevant user characteristics which can reasonably be expected to be found in a wide range of applications. Ideally, any user population for subsequent products would be a subset of the user groups thus defined. Table 1 presents the five defined user groups together with the screening criteria for each group. The different user groups reflect possible differences in the abilities of potential end users. Thus the HCPs in group 1 and CGs in group 2 interact with the device in a different way compared to the other groups as they inject into a patient rather than into themselves. HCPs also have clinical knowledge and training, which will positively affect their performance with the device in comparison to lay users (groups 2-6). CGs in group 2 are expected to have full command of their mental and physical abilities; therefore, they are likely to perform better than participants with impairments in groups 3-5.

Diabetics with retinopathy (DRs, group 3), diabetics with neuropathy (DNs, group 4), and arthritic patients (ARs, group 5) were also separated into distinct groups based on the type of impairment. Here, participants in group 3 have visual impairments, participants in group 4 have tactile impairments, and participants in group 5 have motor impairments. Each of these groups therefore may present different challenges for user interface design.

Sex, age, and previous experience in device use were not considered as specific attributes to be examined individually in this study. Instead, each user group was recruited so as to achieve a representative mix or range of these characteristics.

It is currently recommended to have 5-8 participants per user group for formative studies. ${ }^{12}$ This range has been defined, based on experience, so as to be large enough to capture the whole range of behaviors within a user group. It has not been selected to reach a particular statistical significance of the results. The target number of participants

Table I Definition of the user groups and screening criteria for each group

\begin{tabular}{|c|c|c|c|c|}
\hline Group & Definition (abbreviation) & Property & Screening criteria and target composition & Target size \\
\hline Group I & $\begin{array}{l}\text { Health care } \\
\text { professionals (HCP) }\end{array}$ & $\begin{array}{l}\text { Healthy } \\
\text { qualified user }\end{array}$ & Registered nurses, diabetes specialist nurses & 9 \\
\hline Group 2 & Caregivers (CG) & Lay user & $\begin{array}{l}\text { Healthy adult fit to administer injections. No particular } \\
\text { experience or training }\end{array}$ & 9 \\
\hline Group 3 & $\begin{array}{l}\text { Diabetics with } \\
\text { retinopathy (DR) }\end{array}$ & Impaired vision & $\begin{array}{l}\text { Approximately } 50 \% \text { pen users and the rest non-pen users } \\
\text { (eg, people who use infusion sets, syringes, or oral medication) }\end{array}$ & 9 \\
\hline Group 4 & $\begin{array}{l}\text { Diabetics with } \\
\text { neuropathy (DN) }\end{array}$ & $\begin{array}{l}\text { Impaired tactile } \\
\text { perception }\end{array}$ & $\begin{array}{l}\text { Approximately } 50 \% \text { pen users and the rest non-pen users } \\
\text { (eg, people who use infusion sets, syringes, or oral medication) }\end{array}$ & 9 \\
\hline Group 5 & Patients with arthritis (AR) & $\begin{array}{l}\text { Impaired } \\
\text { dexterity }\end{array}$ & $\begin{array}{l}\text { Male-to-female ratio approximately } \mathrm{I}: 2 \text {. Approximately } 50 \% \\
\text { with pen experience, remainder without device experience }\end{array}$ & 9 \\
\hline All groups & & $\begin{array}{l}\text { Age } \\
\text { Education } \\
\text { Cognitive skills }\end{array}$ & $\begin{array}{l}\text { Between } 18 \text { and } 70 \text { years of age } \\
\text { Some education expected } \\
\text { Cognitive capabilities to understand and follow the instructions } \\
\text { for use after the device has been explained to them }\end{array}$ & \\
\hline
\end{tabular}


to be recruited was set to nine per user group, with the aim of reaching at least eight active participants per user group. The absolute minimum number of users was set at five participants per group.

\section{Facilities and equipment}

Usability tests were conducted in the Simulation and Clinical Skills Centre at the Napier University in Edinburgh, UK, and at the Clinical Skills Suite at Glasgow University in Glasgow. The setup was the same at both facilities, with a basic meeting room used for conducting training with the participants and a hospital room with video recording facilities for participants to perform tasks with the device. This setting was selected to reflect HCP use while providing comparable light and noise levels to what would be encountered in home use. In the hospital rooms, mannequins (Nursing Anne, Laerdal Medical AS, Laerdal, Norway) were used for the injections performed by user groups 1 and 2 , whereas groups 3, 4, and 5 injected into an injection pad (Ypsomed AG). The equipment used for the injections was the YpsoMate ${ }^{\mathrm{TM}}$ disposable autoinjector with water-filled syringes (Ypsomed AG).

\section{Procedure}

A market research agency (Progressive Partnership Ltd, Glasgow, UK) recruited participants across the five groups, according to the screening criteria defined in Table 1. The participants were scheduled to attend an individual 55-minute session at either of the two facilities. The activities carried out by each participant were 1) read and sign a consent form, 2) respond to a prestudy questionnaire, 3) receive training in device use, 4) complete a distraction task, and 5) conduct the handling tests. The detailed sequence of events during the session is depicted in Figure 3.

On arrival to the study venue, each participant was greeted and invited to the training room by a researcher. The participant was asked to sign a consent form and respond to a prestudy questionnaire, which captured some personal details including their experience with similar devices. Participants then received training, consisting of the following steps: 1) the researcher provided a short verbal introduction to the device, 2) the participant read the IFU, and 3) the researcher demonstrated an injection. This training format, ie, a professional describing and demonstrating the device to the trainee without the trainee actually handling the device, was selected as a reasonable representation of how patients are expected to be trained in reality ( $\mathrm{L}$ Kalt, Ypsomed AG, personal communication, May 2014). Throughout the training session, the

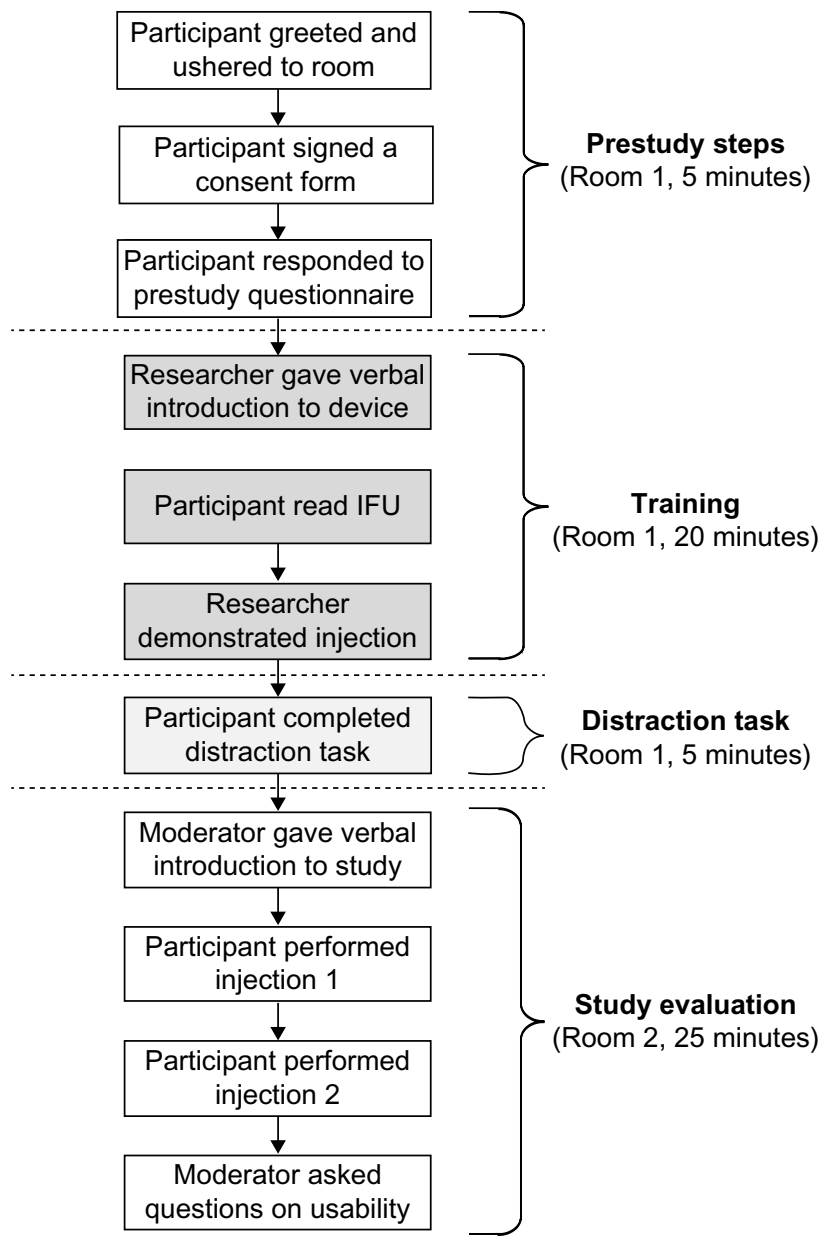

Figure 3 Sequence of events during the handling tests. Abbreviation: IFU, instructions for use.

participant was allowed to ask any questions. Any difficulties participants had in understanding the IFU or training were recorded by the researcher.

Following training, the researcher asked each participant to complete a short distraction task in order to minimize short-term memory recall for the study session. This consisted of two eye tests 1) a Snellen eye chart to measure the participant's distance visual acuity and 2) a Jaeger eye chart to measure the participant's near visual acuity. Once the distraction task was complete, the participant was invited to the study room for the evaluation session, where they were introduced to the moderator. The moderator began by providing a short introduction to the evaluation and then responded to any questions. Participants were also informed at this stage that they could refer to the IFU at any time.

Each participant was then asked to perform two injections, which were video recorded and observed by the moderator who was present in the room at all times. Participants in groups 3-5 simulated the injection using an injection pad on the table. 
However, two participants in each of these groups held the pad onto their abdomen for one of the injections in order to evaluate a simulated self-injection. The order of pad positioning during injection was alternated randomly across participants. To simulate injecting the device into another person, HCPs (group 1) and CGs (group 2) injected the device into the upper arm of a mannequin lying on a hospital bed. During the injections, the moderator observed and recorded any usability issues, consisting of use errors, near misses, assistance required, and references to the IFU. The final set of questions involved asking the participants to rate on a 5-point scale the comprehensibility of the IFU and training and the level of hand comfort and confidence when performing injections.

\section{Results \\ Participants}

The characteristics of the participants in the study are presented in Table 2. A total of 45 participants were recruited, of whom 43 participated in the study. The target number of nine participants was reached in two groups, with the other three groups each having eight participants. Overall, $77 \%$ of the participants were female, $47 \%$ had previous experience using pen injectors, and $60 \%$ reported suffering from some kind of impairment. The mean age of the participants was 49 years, with a range from 19 to 83 years.

\section{Injection success rate, confidence, comfort, and IFU rating}

All participants were successful (ie, required no assistance) in performing the first injection, which corresponded to a $100 \%$ success rate. Everybody except one person in the DR group succeeded in performing the second injection, leading to a success rate of $98 \%$ for this injection. All injections performed into a pad held onto the abdomen and into a mannequin were successful. The detailed results are given in Figure 4.
Figure 5 presents the self-reported data on confidence in using the device. About $70 \%$ of the participants reported that they would "strongly agree" with the statement that they felt confident in using the YpsoMate ${ }^{\mathrm{TM}}$ (Ypsomed AG) and $28 \%$ reported that they would "agree" with this statement. The combined rating for the two categories (the highest two ratings on the 5-point scale) is $98 \%$ of all participants. Looking at the rating per user group, it appears that $100 \%$ of participants in all groups except the DR group would either agree or strongly agree that they felt confident in using the device.

About $49 \%$ of the participants rated the YpsoMate ${ }^{\mathrm{TM}}$ (Ypsomed AG) as "very comfortable" to use and 44\% rated it as "comfortable" to use, giving a combined result of $93 \%$ of participants rating the device as at least "comfortable" to use (the two top ratings on the scale). None of the participants rated the YpsoMate ${ }^{\mathrm{TM}}$ (Ypsomed AG) as "uncomfortable" to use, with the remaining $7 \%$ rating the degree of comfort as "neutral". The results per user group are shown in Figure 6.

Figure 7 presents the reported degree of comprehensibility of the IFU. About $51 \%$ of the participants rated the IFU as "very easy to understand" and $47 \%$ rated it as "easy to understand", bringing the total to $98 \%$ of participants finding the IFU easily comprehensible.

The training was rated as "very easy to understand" by $72 \%$ of participants, with $26 \%$ finding the training "easy to understand", resulting in a total of $98 \%$ rating the training to various degrees easily understandable. The breakdown per group is provided in Figure 8.

\section{Use errors, deviations from IFU procedure, and references to IFU}

A use error was defined as an event which potentially could lead to the participant failing a user task. It is important to distinguish between use errors, representing potential sources

Table 2 Participant characteristics

\begin{tabular}{|c|c|c|c|c|c|c|}
\hline Group & $\mathbf{N}$ & Sex & Age & Handedness & Pen experience & Self-reported impairments \\
\hline $\begin{array}{l}\text { I. Health care } \\
\text { professionals (HCP) }\end{array}$ & 10 & $\begin{array}{l}9 \text { female, } \\
\text { I male }\end{array}$ & 38-54, mean 45 & $\begin{array}{l}\text { I left-handed, } \\
9 \text { right-handed }\end{array}$ & $\begin{array}{l}6 \text { naïve, } \\
4 \text { experienced }\end{array}$ & None \\
\hline 2. Caregivers (CG) & 9 & $\begin{array}{l}6 \text { female, } \\
3 \text { male }\end{array}$ & 19-52, mean 37 & $\begin{array}{l}\text { I left-handed, } \\
8 \text { right-handed }\end{array}$ & $\begin{array}{l}6 \text { naïve, } \\
3 \text { experienced }\end{array}$ & $\begin{array}{l}\text { I with arthritis, I with vision impairment, I with } \\
\text { dyslexia, } 6 \text { without impairments }\end{array}$ \\
\hline $\begin{array}{l}\text { 3. Diabetics with } \\
\text { retinopathy (DR) }\end{array}$ & 8 & $\begin{array}{l}6 \text { female, } \\
2 \text { male }\end{array}$ & 34-76, mean 59 & $\begin{array}{l}\text { I left-handed, } \\
7 \text { right-handed }\end{array}$ & $\begin{array}{l}4 \text { naïve, } \\
4 \text { experienced }\end{array}$ & $\begin{array}{l}\text { All reported some degree of blurriness of vision } \\
\text { in one or both eyes }\end{array}$ \\
\hline $\begin{array}{l}\text { 4. Diabetics with } \\
\text { neuropathy (DN) }\end{array}$ & 8 & $\begin{array}{l}5 \text { female, } \\
3 \text { male }\end{array}$ & 22-83, mean 5I & $\begin{array}{l}\text { I left-handed, } \\
7 \text { right-handed }\end{array}$ & $\begin{array}{l}\text { I naïve, } \\
7 \text { experienced }\end{array}$ & $\begin{array}{l}\text { I with blurred vision, } 2 \text { with tenderness in } \\
\text { hands, } 2 \text { with pins and needles in hands, } 2 \text { with } \\
\text { numbness in hands, I without any impairments }\end{array}$ \\
\hline $\begin{array}{l}\text { 5. Patients with } \\
\text { arthritis (AR) }\end{array}$ & 8 & $\begin{array}{l}7 \text { female, } \\
\text { I male }\end{array}$ & 43-70, mean 58 & $\begin{array}{l}0 \text { left-handed, } \\
8 \text { right-handed }\end{array}$ & $\begin{array}{l}6 \text { naïve, } \\
2 \text { experienced }\end{array}$ & $\begin{array}{l}\text { All reported varying degrees of stiffness, soreness, } \\
\text { and numbness in fingers, hands, and wrists }\end{array}$ \\
\hline Overall & 43 & $\begin{array}{l}33 \text { female, } \\
10 \text { male }\end{array}$ & 19-83, mean 49 & $\begin{array}{l}4 \text { left-handed, } \\
39 \text { right-handed }\end{array}$ & $\begin{array}{l}23 \text { naïve, } \\
20 \text { experienced }\end{array}$ & 26 with impairments, 17 without impairments \\
\hline
\end{tabular}




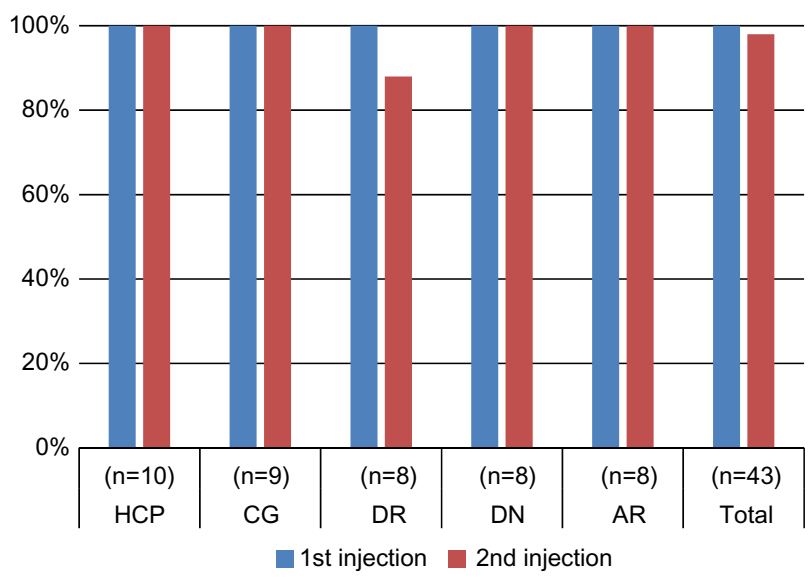

Figure 4 Observed injection success rates for the first and second injection, per user group.

Note: An injection was deemed successful when all user tasks could be completed by the participant without any assistance.

Abbreviations: $\mathrm{HCP}$, health care professionals; CG, caregivers; DR, diabetics with retinopathy; $\mathrm{DN}$, diabetics with neuropathy; $A R$, patients with arthritis.

of failure for individual tasks, and actual injection failure as described in the previous section. Participants may thus well commit use errors without necessarily failing a task or the injection.

Table 3 presents an overview of the observed use errors across all user tasks. Overall, 23 errors were seen across all 86 injections, corresponding to a rate of 0.27 per injection. Considering that no more than one use error was observed during any injection, this translates into $73 \%$ of all injections being performed without any error. Except one use error committed during the second user task, "Place autoinjector on injection pad", all errors occurred during the fifth task, "Continue holding autoinjector for 5 seconds" after the end of injection. The number of errors varied significantly between

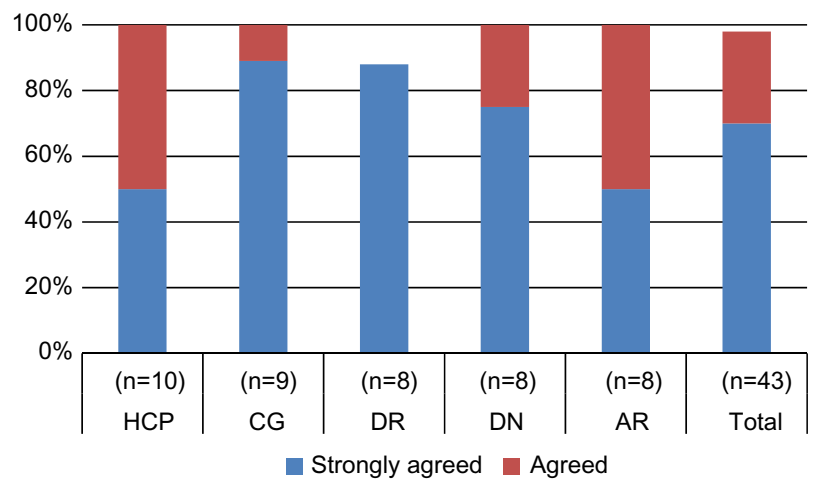

Figure 5 Reported degree of confidence when using the YpsoMate ${ }^{\mathrm{TM}}$; number of participants who "strongly agreed" or "agreed" that they felt confident when using the YpsoMate ${ }^{\mathrm{TM}}$.

Note: The "strongly agree" and "agree" ratings are the two highest ratings on the 5-point scale.

Abbreviations: $\mathrm{HCP}$, health care professionals; $\mathrm{CG}$, caregivers; DR, diabetics with retinopathy; $D N$, diabetics with neuropathy; $A R$, patients with arthritis.

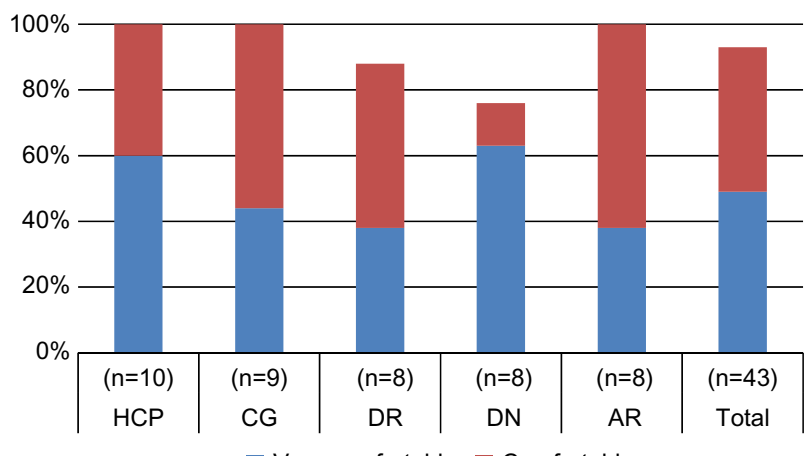

Very comfortable Comfortable

Figure 6 Reported degree of comfort in using the YpsoMate ${ }^{\mathrm{TM}}$; number of participants who rated their comfort in using the YpsoMate ${ }^{\mathrm{TM}}$ as "very comfortable" or "comfortable".

Notes: The "very comfortable" and "comfortable" ratings are the two highest ratings on the 5-point scale. The three participants who did not rate the YpsoMate ${ }^{\mathrm{TM}}$ as either "very comfortable" or "comfortable" to use, all rated the degree of comfort as "neutral" (the third rating on the 5-point scale).

Abbreviations: HCP, health care professionals; CG, caregivers; DR, diabetics with retinopathy; DN, diabetics with neuropathy; $A R$, patients with arthritis.

groups, with DNs and ARs having the highest numbers and DRs the lowest. For all groups except DRs, the number of errors was higher for the second injection. No user errors were observed during injections into a pad held onto the abdomen.

In addition to the user errors, a couple of usability issues and deviations from the procedure as described in the IFU were observed. One participant (in the AR group, corresponding to $2 \%$ of the overall number) had some difficulties in removing the cap. Three participants $(1 \mathrm{CG}, 1 \mathrm{DR}$, and $1 \mathrm{DN}$, equivalent to $7 \%$ of all participants) reported not hearing the first click. A total of nine participants (four in

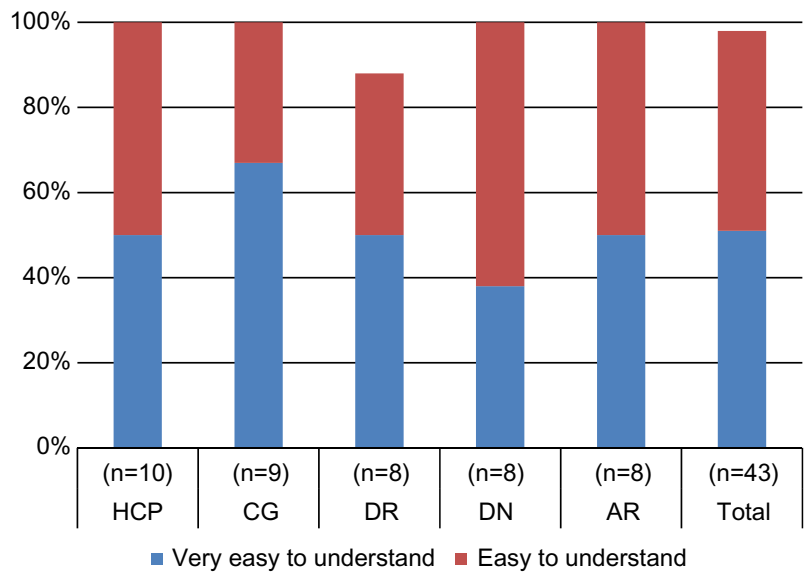

Figure 7 Reported degree of comprehensibility of the IFU; number of participants who rated the IFU as "very easy to understand" or "easy to understand".

Note: The "very easy to understand" and "easy to understand" ratings are the two highest ratings on the 5 -point scale.

Abbreviations: IFU, instructions for use; HCP, health care professionals; CG, caregivers; DR, diabetics with retinopathy; DN, diabetics with neuropathy; AR, patients with arthritis. 


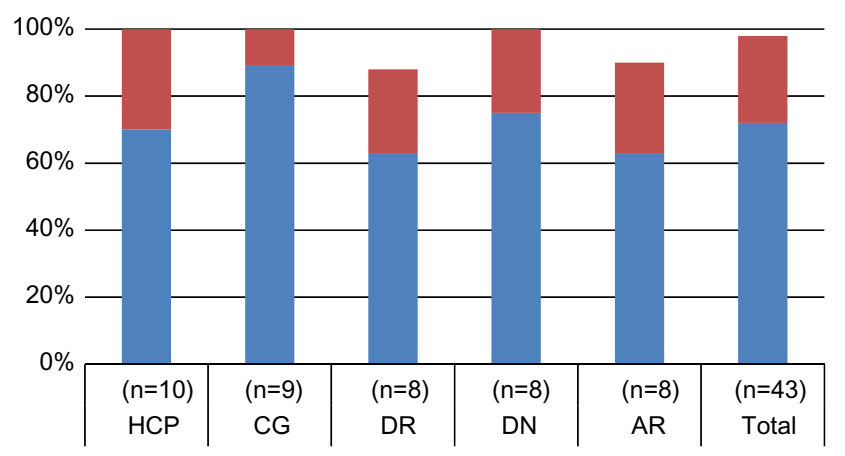

Very easy to understand Easy to understand

Figure 8 Reported degree of comprehensibility of the training; number of participants who rated the training as "very easy to understand" or "easy to understand".

Note: The "very easy to understand" and "easy to understand" ratings are the two highest ratings on the 5 -point scale.

Abbreviations: $\mathrm{HCP}$, health care professionals; CG, caregivers; DR, diabetics with retinopathy; DN, diabetics with neuropathy; $A R$, patients with arthritis.

the HCP group, one in the CG group, and four in the DN group, corresponding to $21 \%$ of all the participants) either intentionally or unintentionally did not observe the window and the plunger rod during the injection as mentioned in the IFU. This deviation from IFU procedure was observed in all types of injections (into a pad on table, into a pad on abdomen, and into a mannequin).

The number of references made to the IFU during each injection is shown in Table 4. The overall rate was 0.53 for the first and 0.14 for the second injection. The rates for each user group vary widely, with CGs making no reference to the IFU in any injection and DRs and ARs making more than one reference each during the first injection. The rate was seen to decrease between the first and second injection in all user groups.

\section{Time required to complete the injections}

Table 5 provides the time required to complete the injections for the different user groups. The average time across all participants decreased from 34.2 seconds for the first injection to 21.0 seconds for the second injection. For the individual user groups, the average time for the first injection varied by almost $50 \%$ between the longest (DN) and the shortest (CG) times. Much smaller variations between user groups were observed for the second injection.

\section{Discussion}

The characteristics of the participants are comparable to what has been reported in other studies, with a range of ages and different degrees of experience in device use. ${ }^{18,19}$ However, the presence and variety of disabilities are wider than in other studies, except for the case where a broad user population has been explicitly defined. ${ }^{16}$

With the exception of a single occurrence in the second injection, all injections in the study were completed successfully. The participant who failed in the second injection, a diabetic with retinopathy suffering from impaired vision and arthritis, made the mistake of orienting the device upside down and was therefore unable to complete the injection. It should be noted that this participant performed the first

Table 3 Observed use errors per user group and injection

\begin{tabular}{|c|c|c|c|c|c|c|c|c|c|c|c|c|}
\hline \multirow[t]{2}{*}{ User task } & \multicolumn{2}{|c|}{$\operatorname{HCP}(n=10)$} & \multicolumn{2}{|c|}{ CG $(n=9)$} & \multicolumn{2}{|c|}{ DR $(n=8)$} & \multicolumn{2}{|c|}{ DN $(n=8)$} & \multicolumn{2}{|c|}{$\operatorname{AR}(n=8)$} & \multicolumn{2}{|c|}{ Total $(n=43)$} \\
\hline & Ist & 2nd & lst & 2nd & lst & 2nd & lst & 2nd & Ist & 2nd & lst & 2nd \\
\hline I. Remove protective cap & & & & & & & & & & & 0 & 0 \\
\hline $\begin{array}{l}\text { 2. Place autoinjector on } \\
\text { injection pad }\end{array}$ & & & & & & I & & & & & 0 & 1 \\
\hline $\begin{array}{l}\text { 3. Push autoinjector down, first } \\
\text { click signals start of injection }\end{array}$ & & & & & & & & & & & 0 & 0 \\
\hline $\begin{array}{l}\text { 4. Hold autoinjector until } \\
\text { second click signals end } \\
\text { of injection }\end{array}$ & & & & & & & & & & & 0 & 0 \\
\hline $\begin{array}{l}\text { 5. Continue holding } \\
\text { autoinjector for } 5 \text { seconds }\end{array}$ & 2 & 3 & 2 & 3 & $\mathrm{I}$ & & 2 & 4 & 2 & 3 & 9 & 13 \\
\hline 6. Remove autoinjector & & & & & & & & & & & 0 & 0 \\
\hline 7. Dispose of autoinjector & & & & & & & & & & & 0 & 0 \\
\hline Sum over all steps & 2 & 3 & 2 & 3 & 1 & I & 2 & 4 & 2 & 3 & 9 & 14 \\
\hline Rate (occurrence/n) & 0.20 & 0.30 & 0.22 & 0.33 & 0.13 & 0.13 & 0.25 & 0.5 & 0.25 & 0.38 & 0.21 & 0.33 \\
\hline $\begin{array}{l}\text { Number of injections } \\
\text { performed without any } \\
\text { error, } \mathrm{n}(\%)\end{array}$ & $8(80 \%)$ & 7 (70\%) & 7 (78\%) & $6(67 \%)$ & 7 (88\%) & 7 (88\%) & $6(75 \%)$ & $4(50 \%)$ & $6(75 \%)$ & $5(63 \%)$ & $34(79 \%)$ & $29(67 \%)$ \\
\hline
\end{tabular}

Notes: A user error is defined as an event which could potentially lead the participant to fail at a user task. No participant made more than one error during any single injection.

Abbreviations: HCP, health care professionals; CG, caregivers; DR, diabetics with retinopathy; DN, diabetics with neuropathy; AR, patients with arthritis. 
Table 4 References to IFU per user group and injection

\begin{tabular}{|c|c|c|c|c|c|c|c|c|c|c|c|c|}
\hline \multirow[t]{2}{*}{ User task } & \multicolumn{2}{|c|}{$\operatorname{HCP}(n=10)$} & \multicolumn{2}{|c|}{ CG $(n=9)$} & \multicolumn{2}{|c|}{$\operatorname{DR}(n=8)$} & \multicolumn{2}{|c|}{ DN $(n=8)$} & \multicolumn{2}{|c|}{$\operatorname{AR}(n=8)$} & \multicolumn{2}{|c|}{ Total $(n=43)$} \\
\hline & Ist & 2nd & Ist & 2nd & Ist & 2nd & Ist & 2nd & Ist & 2nd & Ist & 2nd \\
\hline I. Remove protective cap & 3 & & & & & 1 & I & & I & & 5 & I \\
\hline 2. Place autoinjector on injection pad & & & & & I & & I & & 4 & & 6 & 0 \\
\hline $\begin{array}{l}\text { 3. Push autoinjector down, first click } \\
\text { signals start of injection }\end{array}$ & & & & & & & & & & & 0 & 0 \\
\hline $\begin{array}{l}\text { 4. Hold autoinjector until second } \\
\text { click signals end of injection }\end{array}$ & & & & & 2 & I & & I & & & 2 & 2 \\
\hline $\begin{array}{l}\text { 5. Continue holding autoinjector } \\
\text { for } 5 \text { seconds }\end{array}$ & & & & & 4 & 2 & I & & I & & 6 & 2 \\
\hline 6. Remove autoinjector & & & & & & & & & & & 0 & 0 \\
\hline 7. Dispose of autoinjector & & & & & I & $\mathrm{I}$ & & & 3 & & 4 & I \\
\hline Sum over all steps & 3 & 0 & 0 & 0 & 8 & 5 & 3 & I & 9 & 0 & 23 & 6 \\
\hline Rate (occurrence/n) & 0.30 & 0 & 0 & 0 & 1.00 & 0.63 & 0.38 & 0.13 & 1.13 & 0 & 0.53 & 0.14 \\
\hline
\end{tabular}

Abbreviations: IFU, instructions for use; HCP, health care professionals; CG, caregivers; DR, diabetics with retinopathy; DN, diabetics with neuropathy; AR, patients with arthritis.

injection correctly without any error or deviation but then, after having failed in the second injection, appeared absentminded and confused, and when asked was unable to explain what led to the mistake during the second attempt. The moderator was also unable to identify any apparent reason for the event. This injection failure is therefore attributed to temporary user inadvertence, and thus is not believed to have any direct relation to the device, the IFU, or the training.

Virtually all participants reported high rates of confidence and hand comfort in using the device. The same holds for the rating of understanding of IFU and training. There were no meaningful differences in the scores reported by the different user groups. It may be noted that the results compare favorably with similar evaluations reported in the literature. In these studies comparing different devices, the scores observed for the most preferred devices were generally lower than the ones found in the present study. ${ }^{17,19}$

With the exception of the failed second injection attempt, all observed user errors were due to users not holding the device for a sufficient time after injection. Interestingly, this

Table 5 Time required to complete the injections

\begin{tabular}{|c|c|c|c|c|}
\hline \multirow[t]{2}{*}{ User group } & \multicolumn{2}{|c|}{$\begin{array}{l}\text { First } \\
\text { injection (s) }\end{array}$} & \multicolumn{2}{|c|}{$\begin{array}{l}\text { Second } \\
\text { injection (s) }\end{array}$} \\
\hline & Mean & Range & Mean & Range \\
\hline $\begin{array}{l}\mathrm{HCP}(n=10) \text {, injection into } \\
\text { mannequin }\end{array}$ & 35.5 & $19-47$ & 26.1 & $17-39$ \\
\hline $\begin{array}{l}C G(n=9) \text {, injection into } \\
\text { mannequin }\end{array}$ & 28.6 & $16-57$ & 22.6 & $14-29$ \\
\hline DR $(n=8)$, injection into pad & 34.1 & $19-56$ & 22.6 & $20-30$ \\
\hline DN $(n=8)$, injection into pad & 53.0 & $20-203$ & 21.8 & $14-40$ \\
\hline AR $(n=8)$, injection into pad & 32.8 & $17-66$ & 19.9 & $13-38$ \\
\hline Total $(n=43)$ & 34.2 & $17-203$ & 21.0 & $13-40$ \\
\hline
\end{tabular}

Abbreviations: $\mathrm{HCP}$, health care professionals; $\mathrm{CG}$, caregivers; $\mathrm{DR}$, diabetics with retinopathy; DN, diabetics with neuropathy; AR, patients with arthritis. error was more common in the second injection compared to the first. It was committed by all user groups to varying degrees. In some cases, users forgot the holding time and removed the device directly after the second click. However, in many cases, the users attempted to respect the hold time but nevertheless removed the autoinjector too early. There were also some observations of users holding for longer than the required time (data not shown). It thus appears that holding for a specific time period without any external aid, admittedly a subjective measure, is the most challenging task during the entire injection procedure.

Results on holding time are not often reported in the literature, but where they are, it is found that users often have difficulties respecting the defined time. ${ }^{17,22}$ It is worth mentioning that most autoinjectors currently on the market do not have an audible click at the end of injection and do not require a specific holding time after the end of injection in the IFU. Instead they specify an overall holding time after the first click, ie, start of injection, which is supposed to cover the injection itself as well as a holding time after the injection has been completed. ${ }^{23-28}$ Furthermore, it can be debated whether there actually is a need to continue holding after the injection is complete. Two marketed autoinjectors which include an end-of-injection click do not require patients to further hold and count after this second click. ${ }^{29,30}$ Two other autoinjectors with end-of-injection clicks instruct patients to hold and count only in case they do not hear the second click. ${ }^{31,32}$ Although no specific studies on the influence of holding time after injection on treatment outcome have been found in the literature, the fact that this step is omitted for devices with end-of-injection clicks is a strong indication that it may not be clinically necessary. Furthermore, simulated absorption studies on epinephrine have also shown that at least for this 
drug, the complete amount is absorbed already early in the injection phase..$^{33,34}$

The fact that holding after injection appears to be of questionable clinical relevance and at the same time is the largest source of user error suggests that this user task may not be necessary, and its removal from the IFU may be considered. If the task is maintained, however, it is recommended that the corresponding description in the IFU as well as the training be reworked and improved.

It is important to note that in the present study, none of the users removed the autoinjector before the end of the actual injection, in spite of some of them not hearing the first click and others, for different reasons, not observing the plunger rod. This points to the significance of the dual feedback provided by the device. It appears that the presence of both visible (plunger rod movement) and audible (start and end click) signals in the YpsoMate ${ }^{\mathrm{TM}}$ (Ypsomed AG) renders the handling procedure robust enough to allow for a certain variability in user behavior without impacting the outcome of the injection.

The difficulty in removing the protective cap encountered by one participant in the AR group could be taken as an indication that alternative industrial designs should be considered for device versions to be used by manually impaired patients. However, this issue was observed only once in a total of 30 injections performed by participants with reported dexterity impairments, indicating that the device in its current design can be easily handled by such users. This conclusion is also in line with results from separate studies with female arthritis patients, where it was found that even severely impaired users were able to remove the cap (data not shown).

The number of references to the IFU varied between user groups, with CGs and HCPs consulting the IFU the least and the DRs and ARs the most. This can presumably be explained by the two former user groups being the most experienced (HCPs and CGs) and least impaired and the two latter the most impaired. As could be expected, the occurrence decreased from the first to the second injection.

The average time required to complete the injection was seen to decrease from the first to the second injection in all groups. Considering that the HCP and CG groups took about as long to inject into a mannequin on a bed as the other groups did to inject into a pad on the table, it is believed that the HCPs and CGs would have been much quicker than the other groups under comparable conditions. This would be consistent with the difference in impairments between the groups.

\section{Conclusion}

All participants were able to successfully use the device. Except for a single event, believed to be unrelated to the device, the IFU, or the training, all attempted injections were completed. The device was appreciated by all users with a reported degree of confidence in using the device of $98 \%$, of user comfort of $93 \%$, and of comprehensibility of IFU and training of $98 \%$.

Virtually all observed use errors concerned the holding time after injection, with users either not holding at all or for less than the required time. This finding is consistent with other results reported in the literature. As this handling step also is known to be of debatable clinical relevance, it may be considered for removal from the IFU.

The presence of both audible and visible feedback during injection was seen to be a significant factor contributing to injection success.

The observation that the device can be safely and efficiently used by all tested user groups provides confidence that the device and IFU in their current form will pass future summative testing in specific applications.

\section{Acknowledgment}

The study was conducted by BERGO, UK, with funding from Ypsomed AG.

\section{Disclosure}

Jakob Lange and Philipp Richard work for Ypsomed AG. Nick Bradley works for BERGO, UK. The authors report no other conflicts of interest in this work.

\section{References}

1. French DL, Collins JJ. Advances in parenteral injection devices and aids. In: Pharmaceutical Dosage Forms, Parenteral Medications, Vol 3: Regulations, Validation and the Future. 3rd ed. London, UK: Informa Healthcare; 2010:71-75.

2. Thompson I, Lange J. Pen and autoinjector drug delivery devices. In: Kolhe P, Shah M, Rathore N, editors. Sterile Product Development, AAPS Advances in the Pharmaceutical Sciences Series 6. New York, NY: Springer; 2013:331-356.

3. Willis H, Webster J, Larkin AM, Parkes L. An observational, retrospective, UK and Ireland audit of patient adherence to subcutaneous interferon beta-1a injections using the Rebismart ${ }^{\mathbb{E}}$ injection device. Patient Prefer Adherence. 2014;8:843-851.

4. Boeru G, Milanov I, De Robertis F, et al. Extaviject ${ }^{\circledR} 30 \mathrm{G}$ device for subcutaneous self-injection of interferon beta- $1 \mathrm{~b}$ for multiple sclerosis: a prospective European study. Med Devices. 2013;6:175-184.

5. Seddighzadeh A, Hung S, Selmaj K, et al. Single use autoinjector for peginterferon- $\beta_{1 \mathrm{a}}$ treatment of relapsing-remitting multiple sclerosis: safety, tolerability and patient evaluation data from the Phase IIIb ATTAIN study. Expert Opin Drug Deliv. 2014;11:1713-1720.

6. Devonshire V, Arbizu T, Borre B, et al. Patient-rated suitability of a novel electronic device for self-injection of subcutaneous interferon beta-1a in relapsing multiple sclerosis: an international, single-arm, multicentre, Phase IIIb study. BMC Neurol. 2010;10:28. 
7. Wray S, Armstrong R, Herrman CV, et al. Results from the single-use autoinjector for self-administration of subcutaneous interferon beta-1a in patients with relapsing multiple sclerosis (MOSAIC) study. Expert Opin Drug Deliv. 2011;8:1543-1553.

8. Berteau C, Schwarzenbach F, Donazzolo Y, et al. Evaluation of performance, safety, subject acceptance, and compliance of a disposable autoinjector for subcutaneous injections in healthy volunteers. Patient Prefer Adherence. 2010;4:379-388.

9. Phillips JT, Fox E, Grainger W, Tuccillo D, Liu S, Deykin A. An openlabel, multicentre study to evaluate the safe and effective use of the single-use autoinjector with an Avonex ${ }^{\circledR}$ prefilled syringe in multiple sclerosis subjects. BMC Neurol. 2011;11:126.

10. Pachon JA, Kivitz AJ, Heuer K-U, Pichlmeyer U. Assessing usability, label comprehension, pen robustness and pharmacokinetics of a selfadministered prefilled autoinjector pen of methotrexate in patients with rheumatoid arthritis. SAGE Open Med. 2014;2:1-12.

11. Thompson I. Matching a range of injectors with both patients' and pharma partners' needs. ONdrugDelivery Mag. 2012;(33):36-38. Available from: http://www.ondrugdelivery.com/publications/ Injectable\%20Devices\%202012/Ypsomed.pdf. Accessed April 1, 2015.

12. Association for the Advancement of Medical Instrumentation. Human Factors Engineering - Design of Medical Devices. ANSI/AAMI HE75:2009. Arlington, USA: Association for the Advancement of Medical Instrumentation; 2010.

13. International Standards Organisation. Medical Devices-Application of Usability Engineering to Medical Devices. ISO 62366:2015. Geneva, Switzerland: International Standards Organisation; 2015.

14. Draft Guidance for Industry and Food and Drug Administration Staff. Applying Human Factors and Usability Engineering to Optimize Medical Device Design. Silver Spring, MD: Food and Drug Administration; 2011. Available from: http://www.fda.gov/ medicaldevices/deviceregulationandguidance/guidancedocuments/ ucm259748.htm. Accessed April 1, 2015.

15. Wiklund M, Kendler J, Strochlic AY. Usability Testing of Medical Devices, Boca Raton, FL: CRC Press, Taylor \& Francis Group; 2011.

16. Lange J, Richard P, Bradley N. Usability of devices for self-injection: results of a formative study on a new disposable pen injector. Med Devices. 2014;7:195-203.

17. Guerlain S, Hugine A, Wang L. A comparison of 4 epinephrine autoinjector delivery systems: usability and patient preference. Ann Allergy Asthma Immunol. 2010;104:172-177.

18. Guerlain S, Wang L, Hugine A. Intelliject's novel epinephrine autoinjector: sharps injury prevention validation and comparable analysis with EpiPen and Twinject. Ann Allergy Asthma Immunol. 2010;105:480-484

19. Schwarzenbach F, Dao Trong M, Grange L, et al. Evaluation of performance, safety, subject acceptance, and compliance of a disposable autoinjector for subcutaneous injections in healthy volunteers. Patient Prefer Adherence. 2014;8:199-209.
20. Edwards ES, Edwards ET, Gunn R, Patterson P, North R. Design validation and labeling comprehension study for a new epinephrine autoinjector. Ann Allergy Asthma Immunol. 2013;110:189-193.

21. YpsoMate ${ }^{\mathrm{TM}}$ - The 2-step autoinjector [Product description]. Burgdorf, Switzerland: Ypsomed AG; 2014. Available from: http://www. ypsomed.com/files/documents-ypsomed/yds-downloads/YpsomedYpsoMate-Brochure.pdf. Accessed April 1, 2015.

22. Lombardelli S. Adrenaline auto-injectors: how effective are written patient instructions when used alone in a simulated self-administration test? Poster presented at: 29th Congress of the European Academy of Allergy and Clinical Immunology, June 5-9, 2010, London. Available from: http://www.life-saver.org/wordpress/wp-content/uploads/2010/08/ Lombardelli-poster-EAACI-2010.pdf. Accessed April 1, 2015.

23. Avonex Pen [instructions for use]. Cambridge, MA: Biogen Idec; 2014. Available from: https://www.avonex.com/pdfs/AVONEX-pen.pdf. Accessed April 1, 2015.

24. Humira Autoinjector [instructions for use]. North Chicago, IL: Abbvie; 2014. Available from: http://www.rxabbvie.com/pdf/humirapen_PIL. pdf. Accessed April 1, 2015.

25. Enbrel SureClick Autoinjector [Instructions for use]. Thousand Oaks, CA: Immunex; 2013. Available from: http://pi.amgen.com/united_states/ enbrel/derm/enbrel_piu.pdf. Accessed April 1, 2015.

26. Rebif Rebidose [instructions for use]. Rockland, MA: EMD Serono; 2012. Available from: http://www.rebif.com/resources/pdf/Rebif $\% 20$ Rebidose\%20IFU_Final.pdf. Accessed April 1, 2015.

27. EpiPen [patient information]. Morgantown, WV: Mylan; 2014. Available from: https://www.epipen.com/en/prescribing-information\#Patient. Accessed April 1, 2015.

28. Evzio Autoinjector [patient information]. Richmond, VA: kaleo; 2014. Available from: http://www.evzio.com/pdfs/Evzio-Patient-Information. pdf. Accessed April 1, 2015.

29. Simponi SmartJect autoinjector [instructions for use]. Horsham, PA: Janssen Biotech; 2013. Available from: http://www.simponi.com/shared/ product/simponi/medication-guide.pdf. Accessed April 1, 2015.

30. Pegasys Proclick autoinjector [self-injection training guide]. South San Francisco, CA: Genentech; 2011. Available from: http://prod.pegasys. gene.s3.amazonaws.com/downloads/proClick-guide.pdf. Accessed on April 1, 2015.

31. Trulicity (dulaglutide) single dose pen [instructions for use]. Indianapolis, IN: Eli Lilly; 2014. Available from: http://pi.lilly.com/us/ trulicity-lowdose-ai-ifu.pdf. Accessed April 1, 2015.

32. Aranesp SureClick Autoinjector [patient instructions for use]. Thousand Oaks, CA: Amgen; 2008. Available from: http:/www.accessdata.fda. gov/drugsatfda_docs/label/2010/103951s5197AranespPIUAutoinject or.pdf. Accessed April 1, 2015.

33. Baker TW, Webber CM, Stolfi A, Gonzalez-Reyes E. The TEN study: time epinephrine needs to reach muscle. Ann Allergy Asthma Immunol. 2011;107:235-238.

34. Lieberman P. The 10-second rule and other myths about epinephrine and autoinjectors. Ann Allergy Asthma Immunol. 2011;107:189-190.
Medical Devices: Evidence and Research

\section{Publish your work in this journal}

Medical Devices: Evidence and Research is an international, peerreviewed, open access journal that focuses on the evidence, technology, research, and expert opinion supporting the use and application of medical devices in the diagnosis, treatment and management of clinical conditions and physiological processes. The identification of novel

\section{Dovepress}

devices and optimal use of existing devices which will lead to improved clinical outcomes and more effective patient management and safety is a key feature. The manuscript management system is completely online and includes a quick and fair peer-review system. Visit http://www. dovepress.com/testimonials.php to read real quotes from authors. 